\title{
EDITORIAL
}

\section{Hacia la consolidación de la Gobernanza Ambiental en el Perú}

La gobernanza ambiental es entendida más como un medio que como un fin en sí, para asegurar la conservación del medio ambiente (1), constituye un aspecto clave para el desarrollo de las políticas públicas ambientales del país; sin embargo, los esfuerzos por consolidarla todavía son mínimos en las autoridades de los distintos niveles de gobierno y, por el lado de la sociedad civil en los tomadores de decisiones de las diversas organizaciones sociales. Los acuerdos internacionales de Naciones Unidas la impulsaron desde los inicios de sus decisiones y hoy constituye una dimensión importante en la legislación peruana, como se expresa en la Ley General del Ambiente, que su artículo XI le da ya categoría de principio.

Por la trascendencia del tema y nuestra responsabilidad con la sociedad como universidad, asumimos el compromiso de su fortalecimiento a través de la incorporación como una línea de investigación priorizada, esperando a futuro incrementar los aportes investigativos pertinentes socialmente desde la comunidad académica científica, luego difundir los resultados de los diversos estudios para contribuir de este modo en la mejora del conocimiento y práctica de la gobernanza ambiental.

Es claro que en materia de gobernanza ambiental poco hemos avanzado, pese a tener una normatividad muy comprometida con el medio ambiente y que otorga facultades a los gobiernos regionales y locales para impulsarla en busca de una mayor eficiencia. Las experiencias de Lima y Junín expresan en gran medida esta realidad.

Según el Índice de Ciudades Verdes de Latinoamérica, estudio realizado por Siemens, la gobernanza ambiental de Lima se ubica "debajo del promedio" para la gobernanza ambiental a nivel de Latinoamérica. Esta ubicación se debe principalmente a la asignación fragmentada de recursos y responsabilidades para el manejo del medio ambiente entre múltiples instituciones y niveles de gobierno. En 2006 la municipalidad de Lima creó un departamento especializado en medio ambiente, sin embargo carece de competencia para implementar su propia legislación en este sentido. En los últimos cinco años la ciudad de Lima ha realizado una revisión básica de su sector de desechos, omitiendo agua, saneamiento y calidad del aire, entre otros factores. La mayor parte de las iniciativas de esta política se derivan del Ministerio del Ambiente, en donde se concentra la experticia técnica (2).

La región Junín está constituida por nueve provincias. La ciudad de Huancayo desde la Comisión Ambiental Regional de Junín (CAR Junín), el Comité de Gestión del Área de Conservación Regional del Huaytapallana (CGACR-H), Grupo Técnico de Cambio Climático entre otras organizaciones sociales con limitada participación y compromiso de representantes de otras provincias - desarrolla acciones de carácter ambiental con un impacto en la región poco valorada y reconocimiento por la población. Huancayo tiene como fortalezas la gestión de áreas verdes en la zona urbana, las iniciativas de sensibilización para la segregación de residuos sólidos en fuente y permanentes intentos de mejorar la cobertura de agua para consumo humano; todo un reto a futuro.

La ciudad de Junín tiene en actividad la Comisión Ambiental Municipal (CAM). La Municipalidad Provincial de Junín con apoyo de la comunidad, han denunciado a las empresas mineras que contaminan las aguas del lago Chinchaycocha, y ya han judicializado el tema, en caso de no tener una pronta solución de las autoridades peruanas éstas serían denunciadas ante la Corte Inter-americana de Derechos Humanos de la OEA, asimismo, se procedería a plantear una medida cautelar para suspender las actividades mineras en Cerro de Pasco, sobre todo de las empresas El Brocal, Volcan y Panamerican Silver que son las responsables de la contaminación del segundo lago más grande del Perú, con relaves 
mineros afectando la biodiversidad del ecosistema del lago sin alguna medida de remediación; a la fecha se estima que un 30\% del lago está contaminado poniendo en riesgo a unas 150 especies de aves endémicas y migratorias. Las aguas del lago Chinchaycocha también son fuente de agua del rio Mantaro, que contribuye en la generación de energía eléctrica a unos 14 departamentos de nuestro país. Entre sus fortalezas se encuentran la gestión adecuada de los residuos sólidos orgánicos orientándolos con fines de producción de compost para su uso en la agricultura y las acciones de conservación de los suelos con fines de un cultivo sostenible, un caso representativo es el de la Maca, producto de exportación de Junín.

La ciudad de Concepción tiene en actividad la CAM de Concepción que administra información agraria para brindar información sobre costos de insumos, mercados y estadística que permita a los productores agrícolas decidir oportunamente respecto a oportunidades de negocios; también dispone de maquinaria agrícola que está al servicio de los productores. Entre sus fortalezas se encuentra la gestión adecuada de los residuos sólidos no orgánicos orientándolos con fines económicos y a través del Comité de Vigilancia Ambiental el desarrollo de monitoreos de la calidad del agua (3).

Es oportuno destacar que en el Perú existen políticas y un marco legal ambiental que es el reflejo de los compromisos internacionales que asumimos, éstos instrumentos se encuentran en proceso de consolidación a partir del Ministerio del Ambiente, aunque con algunas deficiencias en su articulación con las organizaciones sociales existentes en las diversas regiones; asimismo existen mecanismos de resolución de conflictos incluido el fomento de conocimientos especializados en la determinación de causas ambientales, que sin embargo no están siendo aplicados adecuadamente en el contexto nacional y local. La gobernanza ambiental peruana, por lo demás tiene pendiente la solución de muchos problemas de carácter socio ambiental, en su mayoría vinculados al sector minero.

Las ciudades de Huancayo, Junín y Concepción, en todo este panorama, exponen hasta hoy mejores desempeños en materia de gobernanza ambiental, aunque en proceso de mejora. Los mayores esfuerzos están concentrados en los temas de tratamiento y accesibilidad de agua para consumo humano, tratamiento de suelos e iniciativas para lograr a futuro el tratamiento de aguas residuales.

\section{Referencias bibliográficas:}

1. Andrade MK, Echevaría MA, Fontaine G, Fuentes JL, Velazco S. Gobernanza ambiental en Bolivia y Perú. Quito: FLACSO; 2011.

2. Siemens AG. Índice de Ciudades Verdes de América Latina, una evaluación comparativa del impacto ecológico de las principales ciudades de América Latina. Reporte final. Munich: Siemens AG; 2010.

3. Perú Ambiental [Internet]. Junín: Bulege W, Semillero de Investigación "Ciudades Verdes"; [actualizada 02/06/2012; citada el 19/07/2012]. Perú Ambiental [01 pantalla]. Disponible en: http://www.peruambiental.blogspot.com 